\title{
Multifunctional Properties Related to Magnetostructural Transitions in Ternary and Quaternary Heusler alloys
}

\author{
Igor Dubenko ${ }^{\mathrm{a} * *}$, Abdiel Quetz ${ }^{\mathrm{a}}$, Sudip Pandey ${ }^{\mathrm{a}}$, Anil Aryal ${ }^{\mathrm{a}}$, Michael Eubank ${ }^{\mathrm{a}}$, Igor \\ Rodionov ${ }^{\mathrm{b}}$, Valerii Prudnikov ${ }^{\mathrm{b}}$, Alexander Granovsky ${ }^{\mathrm{b}}$, Erkki Lahderanta ${ }^{\mathrm{c}}$, Tapas \\ Samanta $^{\mathrm{d}}$, Ahmad Saleheen ${ }^{\mathrm{d}}$, Shane Stadler ${ }^{\mathrm{d}}$, and Naushad Ali ${ }^{\text {a }}$ \\ ${ }^{a}$ Department of Physics, Southern Illinois University, Carbondale, IL 62901 USA \\ ${ }^{\mathrm{b}}$ Faculty of Physics, Moscow State University, Vorob'evy Gory, 11999 I Moscow, Russia \\ ${ }^{c}$ Lappeenranta University of Technology, 53851 Finland \\ ${ }^{\mathrm{d}}$ Department of Physics \& Astronomy, Louisiana State University, Baton Rouge, LA 70803 USA
}

Elsevier use only: Received date here; revised date here; accepted date here

\begin{abstract}
In this report, the results of a study on the effects of compositional variations induced by the small changes in concentrations of the parent components and/or by the substitution of $\mathrm{Ni}$, Mn, or In by an extra element $\mathrm{Z}$, on the phase transitions, and phenomena related to the magnetostructural transitions in off-stoichiometric Ni-Mn-In based Heusler alloys are summarized. The crystal structures, phase transitions temperatures, and magnetic and magnetocaloric properties were analyzed for representative samples of the following systems (all near 15 at.\% indium concentration): Ni-Mn-In, Ni-Mn-In-Si, Ni-Mn-In-B, Ni-Mn-In-Cu, Ni-Mn-In-Cu-B, Ni-Mn-In-Fe, Ni-Mn-In-Ag, and Ni-Mn-In-Al.
\end{abstract}

(C) 2016 Elsevier B.V. All rights reserved

PACS: 75.30Sg.;75.50-y;75.20.En; 65.20+w

Keywords:Heusler alloys; MCE; Magnetoresistance; Multifunctional materials

\section{Introduction}

In spite of the significant progress made in recent years in understanding the multifunctional properties related to magnetostructural transitions (MSTs) in Ni-Mn-In based Heusler alloys, the detailed mechanisms responsible for the MSTs are far from being well understood. A MST is a structural martensitic transition that results in a change of the magnetic state of the material. Magnetic states of high temperature austenitic (AP) and low temperature martensitic (MP) phases in magnetic, offstoichiometric Heusler alloys can be quite different and inhomogeneous. As a result, MSTs are

* Corresponding author. Tel.: +1-618-453-7126; fax: +1-618-453-1056.

E-mail address: igor_doubenko@yahoo.com. 
responsible, not only for large magnetocaloric effects (normal and inverse), but also for a slew of other pronounced physical properties including magnetoelasticity, large Hall effect, giant magnetoresistance, high spin polarization, magnetic shape memory effects, and exchange bias [1-5]. These multi-properties are all a consequence of a magnetostructural phase transition, and are therefore related to each other. Identifying the connections between these properties, and their relationships to the phase transitions, is an important issue in condensed matter physics, as such advances will help in better understanding the origins of MSTs, and to develop new materials for multifunctional applications.

In-based Heusler alloys with nearly 15 at. \% concentration of In undergo MSTs near room temperature that result in sharp changes in the magnetization and related magnetoresponsive phenomena. Due to the delicate balance between electronic, ionic, vibrational, and magnetic energies in the vicinity of the MST, the properties of these alloys are extremely sensitive to any changes in intrinsic parameters, such as chemical composition, type of crystal structure, as well as on extrinsic parameters, such as fabrication techniques and conditions, annealing temperature, applied magnetic field, pressure, rate of heating and cooling, sequence of measurements, and cycling. It is widely believed (see, for example [6]) that the specific features of electronic band structure of the Heusler alloys are responsible for the MST. Therefore the alloy composition, the concentration of valence electrons per atom (e/a), interatomic distances, and crystal structure homogeneity are interconnected major factors affecting the phase transitions and the related phenomena. Following these consideration, the multicomponent alloys with even a small volume fraction of the extra elements, $Z$, present an opportunity to search for desirable properties at ambient temperatures and at accessible magnetic fields.

The changes in e/a ratio and in structural parameters (cell parameters and volume) are commonly considered to be the factors affecting the electronic structure, and therefore the phase stability and MST temperature in solid solutions based on Heusler alloys. However, in the multi-component $\mathrm{Ni}$ Mn-In-Z systems with a small volume fraction of the extra element $Z$, these approaches are not always applicable [see 7,8].
In this report, we summarize the results of our studies on the effects of small changes in concentration of the parent components, and/or by the substitution of $\mathrm{Ni}, \mathrm{Mn}$, or In by an extra element $\mathrm{Z}$ on the phase transitions and phenomena related to the MSTs in offstoichiometric Ni-Mn-In based Heusler alloys.

\section{Experimental procedure}

Polycrystalline samples of $\mathrm{Ni}_{50} \mathrm{Mn}_{35} \mathrm{In}_{12} \mathrm{Si}_{3}$, $\mathrm{Ni}_{50.5} \mathrm{Mn}_{32.32} \mathrm{Cu}_{2.02} \operatorname{In}_{14.14} \mathrm{~B}_{1.01}, \quad \mathrm{Ni}_{50} \mathrm{Mn}_{1-\mathrm{x}} \mathrm{Cu}_{\mathrm{x}} \mathrm{In}_{14} \mathrm{~B}$, $\mathrm{Ni}_{50.5} \mathrm{Mn}_{33.08} \mathrm{Cu}_{1.26} \mathrm{In}_{14.14} \mathrm{~B}_{1.01}, \mathrm{Ni}_{50.51} \mathrm{Mn}_{34.34} \mathrm{In}_{14.14} \mathrm{~B}_{1.01}$, $\mathrm{Ni}_{50} \mathrm{Mn}_{35} \operatorname{In}_{13.5} \mathrm{Al}_{1.5}, \quad \mathrm{Ni}_{50} \mathrm{Mn}_{33.75} \mathrm{Cu}_{1.25} \mathrm{In}_{15}$, $\mathrm{Ni}_{50} \mathrm{Mn}_{35} \mathrm{In}_{11} \mathrm{Si}_{4}, \quad \mathrm{Ni}_{50} \mathrm{Mn}_{34} \mathrm{In}_{16}, \mathrm{Ni}_{49.9} \mathrm{Mn}_{34.9} \mathrm{In}_{15} \mathrm{Ag}_{0.2}$, $\mathrm{Ni}_{49.8} \mathrm{Mn}_{35.26} \mathrm{In}_{14.94}, \mathrm{Ni}_{49.9} \mathrm{Mn}_{35.1} \mathrm{In}_{15}, \mathrm{Ni}_{49.8} \mathrm{Mn}_{34.9} \mathrm{In}_{15.3}$, $\mathrm{Ni}_{50} \mathrm{Mn}_{34} \mathrm{In}_{15}, \quad \mathrm{Ni}_{49.9} \mathrm{Mn}_{34.7} \mathrm{In}_{15.4}, \quad \mathrm{Ni}_{49.6} \mathrm{Mn}_{34.8} \operatorname{In}_{15.2}$, $\mathrm{Ni}_{49.8} \mathrm{Mn}_{34.7} \mathrm{In}_{15.5}, \quad \mathrm{Ni}_{49.6} \mathrm{Mn}_{34.5} \mathrm{In}_{15.9}, \mathrm{Ni}_{49.7} \mathrm{Mn}_{34.8} \mathrm{In}_{15.5}$ and, $\mathrm{Ni}_{46.7} \mathrm{Fe}_{3} \mathrm{Mn}_{34.8} \mathrm{In}_{15.5}, \mathrm{Ni}_{50} \mathrm{Mn}_{34.8} \mathrm{In}_{15.2}$ have been prepared using $4 \mathrm{~N}$ purity metals in an $\mathrm{Ar}$ atmosphere by arc-melting methods, and annealed in high vacuum $(\approx 10-5$ torr $)$ for 24 hours at a temperature of $850{ }^{\circ} \mathrm{C}$. The crystal structures were determined by powder X-ray diffraction methods using $\mathrm{Cu} \mathrm{K \alpha}$ radiation. Thermomagnetic curves $\mathrm{M}(\mathrm{H}, \mathrm{T})$ have been acquire using a superconducting quantum interference device magnetometer (Quantum Design) in the temperature interval $5-400 \mathrm{~K}$ and in magnetic fields up to $50 \mathrm{kOe}$. The measurements have been carried out during heating after the samples were cooled from $400 \mathrm{~K}$ to the starting temperature at zero magnetic field in the zero-field-cooled (ZFC) measurements. Some of magnetization data were collected during the field cooling cycle (FCC). Magnetotransport measurements have been carried out using the standard four-probe method, in the temperature interval $5-400 \mathrm{~K}$ at magnetic fields up to $50 \mathrm{kOe}$. All magnetotransport measurements have been carried out in ZFC conditions. Direct measurements of the adiabatic change of temperature, $\Delta \mathrm{T}_{\mathrm{AD}}$, under an applied magnetic field have been done using an adiabatic magnetocalorimeter (MagEq MMS 801) in a temperature range of $250-350 \mathrm{~K}$, and in magnetic fields up to $1.8 \mathrm{~T}$. The external magnetic fields have been ramped at a rate of up to $20 \mathrm{kOe} / \mathrm{sec}$ during $\Delta \mathrm{T}_{\mathrm{AD}}$ measurements. A differential scanning calorimeter (DSC 8000) has been used to obtain heat flow curves (with a ramp rate of $20 \mathrm{~K} / \mathrm{min}$ during heating and cooling) in the temperature range of 103$573 \mathrm{~K}$. In the measurements under hydrostatic pressure, Daphne (7373) oil was used as the pressure 
transmitting medium. The value of the applied pressure was calibrated by measuring the shift of the superconducting transition temperature of $\mathrm{Pb}$ used as reference manometer $\left(\mathrm{T}_{\mathrm{C}} \sim 7.2 \mathrm{~K}\right.$ at ambient pressure) [9].

\section{Results and discussion}

The phase composition of the compounds have been identified based on the XRD results mostly as a mixture of austenitic cubic (L2 1 or B2) and the martensitic crystal structure modifications at $300 \mathrm{~K}$. The behavior reflects the presence of temperature austenitic/martensitic hysteresis in the vicinity of the room temperature. All samples show ferromagnetic type magnetization curves in high magnetic fields $(\mathrm{H}>1000 \mathrm{Oe})$ at $5 \mathrm{~K}$. The phase transitions of the systems were found to be similar to that of "parent" $\mathrm{Ni}_{50} \mathrm{Mn}_{35} \mathrm{In}_{15}$ compound (see Refs. 1 and 2, for example). The samples show three transition temperatures: $T_{C M}, T_{A} / T_{M}$, and $T_{C}$, where $T_{C M}$ is the Curie temperature of martensitic phase, $T_{A} / T_{M}$ and $T_{C}$ are the temperatures of the direct/inverse martensitic transition (MST) and Curie temperature of austenitic phase, respectively (see Figure 1).

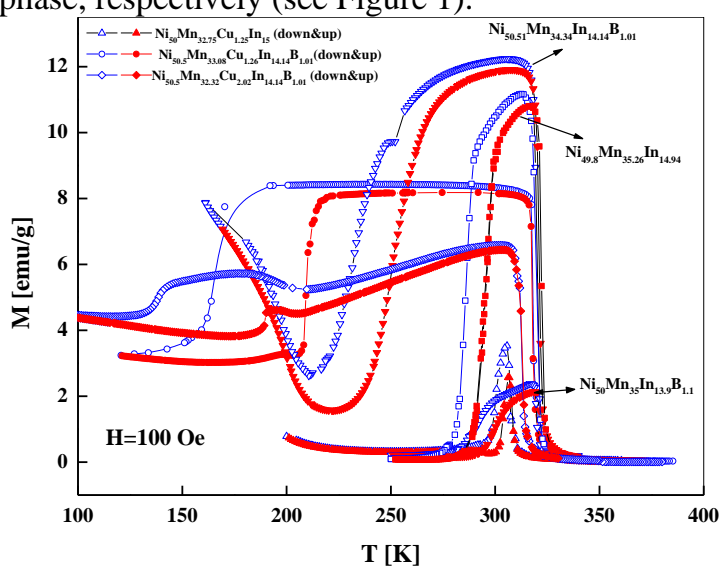

Fig. 1. $\mathrm{M}(\mathrm{H})$ curves obtained at $\mathrm{H}=100$ Oe for some compounds based on $\mathrm{Ni}_{50} \mathrm{Mn}_{35} \mathrm{In}_{15}$.

The heat flow (HF) and $\Delta \mathrm{T}_{\mathrm{AD}}$ curves with respect to temperature demonstrate endothermic peaks and negative values, in the vicinity of the MST, respectively (see Figures 2 and 3). The behavior is a signature of first order transitions. The positive reversible changes in $\Delta \mathrm{T}_{\mathrm{AD}}$ are clearly seen in the vicinity of $\mathrm{T}_{\mathrm{C}}$ (see Figure 3 ). It is necessary to note that several compounds show an irreversibility in the value of $\Delta \mathrm{T}_{\mathrm{AD}}$ for direct and inverse MSTs (see
Figure 3). The sample compositions, transition temperatures $T_{A} / T_{M}$, and $T_{C}$ (determined from $M(T)$ curves at low magnetic field $\mathrm{H}=100 \mathrm{Oe}$ ), along with maximum values of $\Delta \mathrm{T}_{\mathrm{AD}}$, are collected in Table 1 .

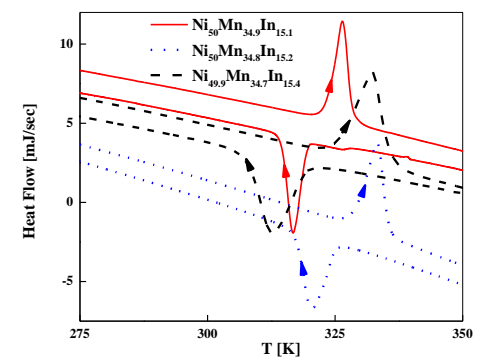

Fig. 2. Heat flow for some samples based on $\mathrm{Ni}_{50} \mathrm{Mn}_{35} \mathrm{In}_{15}$.

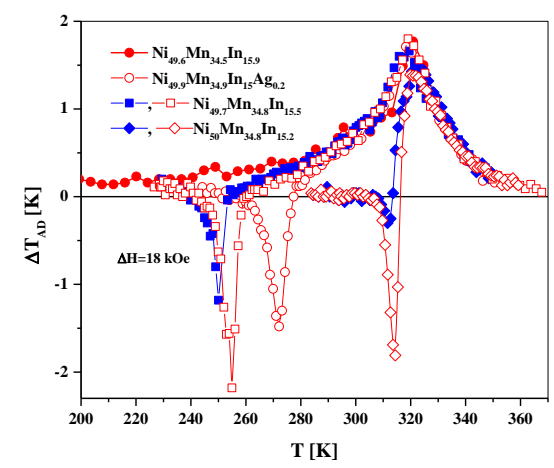

Fig. 3. Temperature dependencies of adiabatic temperature changes obtained at $\Delta \mathrm{H}=18 \mathrm{kOe}$ for Heusler alloys based on $\mathrm{Ni}_{50} \mathrm{Mn}_{35} \operatorname{In}_{15}$.

Some of the compounds based on $\mathrm{Ni}_{50} \mathrm{Mn}_{35} \mathrm{In}_{15}$ demonstrate puzzling and interesting behaviors of magnetoresistance (MR) in close vicinity and below the MST (see Figure 4, showing a part of the full hysteresis of $\mathrm{MR}(\mathrm{H})$ of $\mathrm{Ni}_{50} \mathrm{Mn}_{35} \mathrm{In}_{14} \mathrm{~B}$. For a more detailed consideration see Ref. [8]). The asymmetry in the MR relative to the applied magnetic field can be clearly seen in Figure 4. Such behavior, as well as the irreversibility of $\Delta T_{\mathrm{AD}}$, is most likely related to the presence of the metastable "arrested" austenitic state induced by the external magnetic field in close vicinity of the MST. The thermomagnetic curves under different applied pressures (P) of $\mathrm{Ni}_{50.51} \mathrm{Mn}_{34.34} \mathrm{In}_{14.14} \mathrm{~B}_{1.01}$ compound is shown in Figure 5. As one can see, the MST temperature is extremely sensitive to the pressure, and increases with a rate of 96 K/GP from $237 \mathrm{~K}$ at $\mathrm{P}=0.92 \mathrm{GPa}$. 
A small variation in composition (0.1-2) mol\% relative to $\mathrm{Ni}_{50} \mathrm{Mn}_{35} \mathrm{In}_{15}$ results in a variation in $\mathrm{T}_{\mathrm{C}}$ (from $272 \mathrm{~K}$ to $326 \mathrm{~K}$, see Table 1) and in significant changes in $\mathrm{T}_{\mathrm{M}}$ (from $140 \mathrm{~K}$ to $317 \mathrm{~K}$ ). Such small compositional changes do not strongly affect the e/a ratio (particularly in the case of isoelectronic substitution), nor the crystal cell parameters. However, such variations can change the electron wave function distribution and therefore the electron localization function, providing a change in the covalent bonding that is largely responsible for the stabilization of the high-temperature austenite phase [10]. Obviously, this effect depends on the metallic radius of constituent metals. Therefore, the change in the average metallic radius resulting from the difference of the radii of parent and extra metals $(\Delta \mathrm{R})$ in different atomic sites is a parameter that can be considered to affect the transitions temperatures. The change in effective radius $\left(\Delta \mathrm{R}_{\text {eff }}\right)$, calculated as a sum of the $\Delta \mathrm{R}$ in the atomic sites of $\mathrm{Ni}_{50} \mathrm{Mn}_{35} \mathrm{In}_{15}$ is introduced in the Table 1 . For example, the deficiency of 0.2 at $\%$ of $\mathrm{Ni}$ was counted as $\Delta \mathrm{R}=(-0.2) \times \mathrm{R}_{\mathrm{Ni}}$.

Table 1. Samples composition in Mol. \%, Curie and MST transition temperatures obtained at magnetic field $\mathrm{H}=100 \mathrm{Oe}$, adiabatic temperature change in the vicinity of the transition temperatures, for $\Delta \mathrm{H}=18 \mathrm{kOe}$, and effective metallic radii changes $\left(\Delta \mathrm{R}_{\mathrm{eff}}\right)$ calculated using the metallic radii from Ref. [11]

\begin{tabular}{|l|l|l|l|l|l|}
\hline composition & $\begin{array}{l}\Delta \mathrm{R}_{\text {eff }} \\
{[\mathrm{A}]}\end{array}$ & $\begin{array}{l}\mathrm{T}_{\mathrm{C}} \\
{[\mathrm{K}]}\end{array}$ & $\begin{array}{l}\mathrm{T}_{\mathrm{A}} \\
{[\mathrm{K}]}\end{array}$ & $\begin{array}{l}\Delta \mathrm{T}_{\mathrm{AD}} \\
{[\mathrm{K}],} \\
\mathrm{T}_{\mathrm{A}}\end{array}$ & $\begin{array}{l}\Delta \mathrm{T}_{\mathrm{AD}} \\
{[\mathrm{K}],} \\
\mathrm{T}_{\mathrm{C}}\end{array}$ \\
\hline $\mathrm{Ni}_{50} \mathrm{Mn}_{35} \mathrm{In}_{11} \mathrm{Si}_{4}$ & -1.38 & 272 & 236 & -1 & 0.8 \\
\hline $\mathrm{Ni}_{50} \mathrm{Mn}_{35} \mathrm{In}_{12} \mathrm{Si}_{3}$ & -1.03 & 274 & 252 & -1.5 & 0.9 \\
\hline $\mathrm{Ni}_{50.5} \mathrm{Mn}_{32.32} \mathrm{Cu}_{2.02} \mathrm{In}_{14.14} \mathrm{~B}_{1.01}$ & -0.74 & 310 & 190 & -- & -- \\
\hline $\mathrm{Ni}_{50.5} \mathrm{Mn}_{33.08} \mathrm{Cu}_{1.26} \mathrm{In}_{14.14} \mathrm{~B}_{1.01}$ & -0.72 & 318 & 210 & -- & -- \\
\hline $\mathrm{Ni}_{50.51} \mathrm{Mn}_{34.34} \mathrm{In}_{14.14} \mathrm{~B}_{1.01}$ & -0.64 & 320 & 256 & -- & -- \\
\hline $\mathrm{Ni}_{50} \mathrm{Mn}_{35} \mathrm{In}_{13.5} \mathrm{Al}_{1.5}$ & -0.34 & 318 & 296 & -0.5 & 1.4 \\
\hline $\mathrm{Ni}_{50} \mathrm{Mn}_{33.75} \mathrm{Cu}_{1.25} \mathrm{In}_{15}$ & -0.01 & 307 & 304 & -- & -- \\
\hline $\mathrm{Ni}_{49.8} \mathrm{Mn}_{35.26} \mathrm{In}_{14.94}$ & -0.09 & 323 & 300 & -- & -- \\
\hline $\mathrm{Ni}_{50} \mathrm{Mn}_{34} \mathrm{In}_{15}$ & 0 & 313 & 314 & -- & -- \\
\hline $\mathrm{Ni}_{50} \mathrm{Mn}_{34.8} \mathrm{In}_{15.2}$ & 0.072 & 320 & 319 & -1.8 & 1.5 \\
\hline $\mathrm{Ni}_{49.9} \mathrm{Mn}_{34.9} \mathrm{In}_{15} \mathrm{Ag}_{0.2}$ & 0.12 & 320 & 275 & -- & -- \\
\hline $\mathrm{Ni}_{49.9} \mathrm{Mn}_{35.1} \mathrm{In}_{15}$ & 0.130 & 317 & 305 & -2.1 & 1.6 \\
\hline $\mathrm{Ni}_{49.8} \mathrm{Mn}_{34.9} \mathrm{In}_{15.3}$ & 0.134 & 316 & 308 & -- & -- \\
\hline $\mathrm{Ni}_{49.9} \mathrm{Mn}_{34.7} \mathrm{In}_{15.4}$ & 0.139 & 315 & 315 & -1.3 & 1.7 \\
\hline $\mathrm{Ni}_{49.6} \mathrm{Mn}_{34.8} \mathrm{In}_{15.2}$ & 0.2 & 320 & 270 & -- & -- \\
\hline $\mathrm{Ni}_{49.8} \mathrm{Mn}_{34.7} \mathrm{In}_{15.5}$ & 0.208 & 320 & 269 & -1.1 & 1.7 \\
\hline $\mathrm{Ni}_{49.7} \mathrm{Mn}_{34.8} \mathrm{In}_{15.5}$ & 0.21 & 319 & 262 & -1.6 & 1.5 \\
\hline $\mathrm{Ni}_{46.7} \mathrm{Fe}_{3} \mathrm{Mn}_{34.8} \mathrm{In}_{15.5}$ & 0.28 & 320 & -- & -- & -- \\
\hline $\mathrm{Ni}_{49.6} \mathrm{Mn}_{34.5} \mathrm{In}_{15.9}$ & 0.316 & 321 & -- & -- & -- \\
\hline $\mathrm{Ni}_{50} \mathrm{Mn}_{34} \mathrm{In}_{16}$ & 0.359 & 326 & 140 & -- & -- \\
\hline
\end{tabular}

The ( $\mathrm{T}$ vs. $\Delta \mathrm{R}_{\mathrm{eff}}$ ) phase diagram of the systems based on $\mathrm{Ni}_{50} \mathrm{Mn}_{35} \mathrm{In}_{15}$ is shown in Fig.6. Both critical temperatures $\mathrm{T}_{\mathrm{C}}$ and $\mathrm{T}_{\mathrm{M}}$ show a monotonic

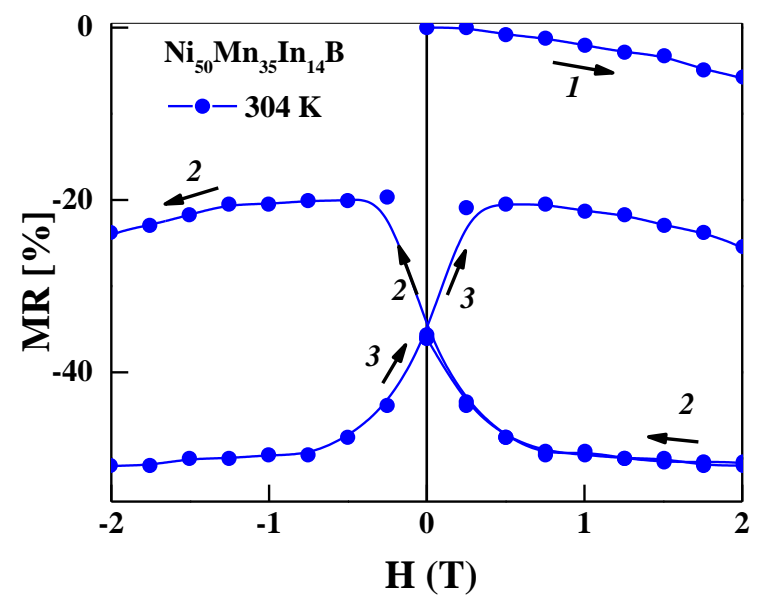

Fig. 4. Part of the magnetic hysteresis of magnetoresistance obtained in close vicinity and below the martensitic transition temperature. Numbers and arrows indicate the magnetization cycles and changes in magnetic field direction.

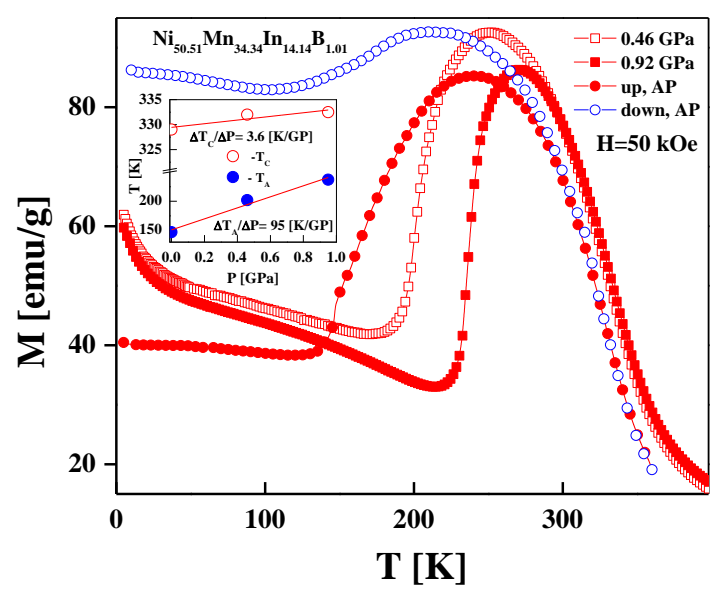

Fig. $5 \mathrm{ZFC}$ and FCC $\mathrm{M}(\mathrm{H})$ curves of $\mathrm{Ni}_{50.51} \mathrm{Mn}_{34.34} \mathrm{In}_{14.14} \mathrm{~B}_{1.01}$ obtained at $\mathrm{H}=50 \mathrm{kOe}$ and at different applied hydrostatic pressures. Inset: Variation of the transition temperatures $T_{C}$ and $\mathrm{T}_{\mathrm{M}}$, open and closed symbol, respectively, with applied pressure. 


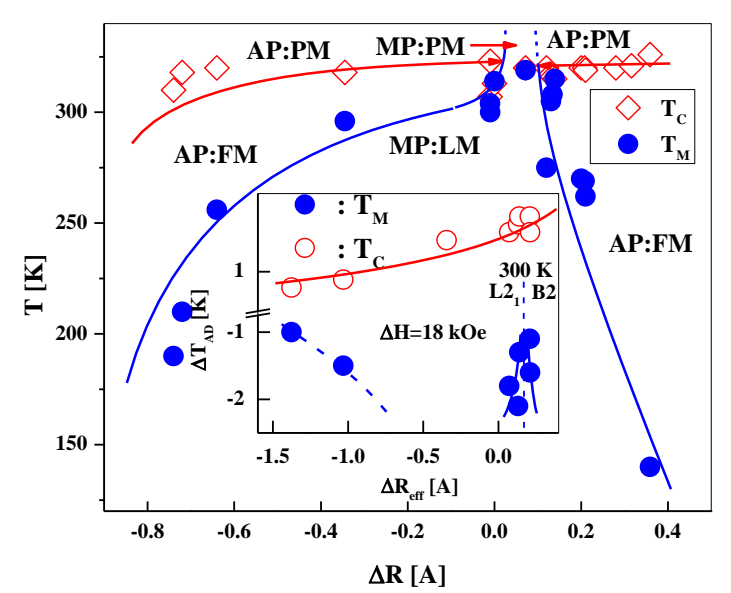

Fig. $6\left(T-\Delta R_{\text {eff }}\right)$-phase diagram of the systems based on $\mathrm{Ni}_{50} \mathrm{Mn}_{35} \mathrm{In}_{15}$. AP and MP, PM, FM, and LM are austenitic and martensitic, paramagnetic, ferromagnetic, and low magnetic phases, respectively. Open and closed symbols are $T_{C}$ and $T_{M}$, respectively. Inset: The changes in $\Delta \mathrm{T}_{\mathrm{AD}}$ with effective radius ( $\Delta \mathrm{R}_{\text {eff }}$ ) for Heusler alloys based on $\mathrm{Ni}_{50} \mathrm{Mn}_{35} \mathrm{In}_{15} . \Delta \mathrm{T}_{\mathrm{AD}}$ in the vicinity of $T_{C}$ and $T_{M}$ are shown by the open and closed symbols, respectively. The vertical dash line indicates $\Delta \mathrm{R}_{\mathrm{eff}}$, where a change of the type of cubic structure has been observed at $300 \mathrm{~K}$ [1].

type of behavior with respect to $\Delta \mathrm{R}_{\mathrm{eff}}$ : $\mathrm{T}_{\mathrm{C}}$ slightly increases and remains nearly constant in (-0.74$0.0018)$ and (0.202-0.37) intervals of $\Delta \mathrm{R}_{\text {eff }}$ changes, $\mathrm{T}_{\mathrm{M}}$ sharply increases/decreases in (-1.93-0.0018) and (0.202-0.37) intervals of $\Delta \mathrm{R}_{\mathrm{eff}}$, respectively. In the vicinity of and above $\Delta R_{\text {eff }}=0$ (i.e. "parent" compound) in the interval: $0.08 \leq \Delta \mathrm{R}_{\mathrm{eff}} \leq 0.16$, the $\mathrm{T}_{\mathrm{M}}$ are found to be equal or larger than $\mathrm{T}_{\mathrm{C}}$, and only the transitions from the strongly correlated PM to the low magnetic state are observed. The $\left|\Delta \mathrm{T}_{\mathrm{AD}}\right|$ related to the MST passes through a minimum near $\Delta \mathrm{R}_{\mathrm{eff}}=-$ 0.17 , and shows a behavior suggesting the existence of two maxima for $-1.03<\Delta \mathrm{R}_{\mathrm{eff}}<0.18$ and $0.205 \leq$ $\Delta \mathrm{R}_{\text {eff }} \leq 0.29$, intervals. $\Delta \mathrm{T}_{\mathrm{AD}}$ in the vicinity of $\mathrm{T}_{\mathrm{C}}$ monotonically increases up to $1.8 \mathrm{~K}$ for $\Delta \mathrm{R}_{\text {eff }}=0.4$. It is interesting to note that the minimum of $\left|\Delta \mathrm{T}_{\mathrm{AD}}\right|$ at the MST is consistent with the changes of the structural type of austenitic phase (B2-L2 1 ) observed in Ref. [1] at room temperature.

\section{Conclusion}

The obtained results show that the local distortion in electron structure induced by small variations in atomic compositions through "local" inhomogeneity can be considered as one of the key factors in temperature stabilization of the martensitic and austenitic phases. The possible presence of the two maxima in $\Delta \mathrm{T}_{\mathrm{AD}}$ near the Heusler alloy with composition $\mathrm{Ni}_{50} \mathrm{Mn}_{35} \mathrm{In}_{15}$ is an interesting subject for future studies. Thus the multifunctional properties of Ni-Mn-In based Heusler alloys may be enhanced, tuned, and adjusted to required technical parameters using small compositional changes. Though the adiabatic temperature change in Heusler alloys is smaller than that of $\mathrm{Gd}$, it seems to be large enough to be useful for magnetic refrigeration purposes.

\section{Acknowledgment}

Work at Southern Illinois University was supported by the U.S. Department of Energy (DOE), Office of Science, Basic Energy Sciences (BES) under Award No. DE-FG02-06ER46291. Work at Louisiana State University was supported by DOE, Office of Science, BES under Award No. DE-FG02-13ER46946. Work at Moscow State University (adiabatic temperature change measurements) was supported by the Russian Foundation for Basic Research under Award No 1202-00095a.

\section{References}

[1] T. Krenke,M.Accet, E.F.Wassermann, X.Moya, L.Manosa, A.Planes, Phys. Rev. B 73 (2006) 174413. [2] I. Dubenko, M. Khan, A. K. Pathak, B. R. Gautam, S. Stadler, N. Ali, J. Magn. Magn. Mat. 321 (2009) 754-757.

[3] I. Dubenko, T. Samanta, A. Kumar Pathak, A. Kazakov, V. Prudnikov, S. Stadler, A. Granovsky, A. Zhukov and N. Ali, J. Magn. Mag. Mat. 324 (2012) 3530 - 3534.

[4] I. Dubenko, A. K. Pathak, S. Stadler, N. Ali, Ya. Kovarskii, V. N. Prudnikov, N. S. Perov, and A. B. Granovsky, Phys. Rev. B 80 (2009) 092408.

[5] A. K. Pathak, M. Khan, B. R. Gautam, S. Stadler, I. Dubenko, N. Ali, J. Magn. Magn. Mat. 321 (2009) 963-965.

[6] P.Entel, V.D.Buchelnikov, V.V. Khovailo, A.T.Zayak, W.A. Adeagbo, M.E. Gruner, H.C. Herper, E.F. Wassermann, J.Phys.D:Appl.Phys. 39 (2006) 865-889.

[7] A. P. Kazakov, V. N. Prudnikov, A. B. Granovsky, A. P. Zhukov, J. Gonzalez, I. Dubenko, 
A. K. Pathak, S. Stadler, N. Ali, Appl. Phys. Lett. 98 131911 (2011).

[8] I. Dubenko, T. Samanta, A. Quetz, A. Saleheen, V. N. Prudnikov, A. B. Granovsky, S. Stadler, N. Ali., Phys. Status Solidi C 11 (2014) 1000-1003.

[9] A. Eiling and J. S. Schilling, J. Phys. F 11 (1981) 623.

[10] E. Liu, W. Wang, L. Feng, W. Zhu, G. Li, J.

Chen, H. Zhang, G. Wu, C. Jiang, H. Xu, F. de Boer, Nature communications (2012) 873 |.

[11] In, "The Crystal Chemistry and Physics of Metals and Alloys", by W.B. Pearson, Wiley-

Interscience, New-York, 1972. 